\title{
O RECURSO À SENSUALIDADE COMO ESTRATÉGIA DO MERCADO GOSPEL
}

\author{
Sandra Duarte de Souza* \\ João Marcos da Silva**
}

\section{RESUMO}

Este artigo tem como objetivo analisar o uso do erotismo e da sedução como parte da estratégia de marketing presente nas produções dos/as "artistas" gospel a partir da década de 1990. Na sociedade de consumo ocidental, o uso da imagem carrega uma carga considerável de exploração de sua corporeidade. Neste sentido, a sensualidade e a erotização visual tornam-se componentes presentes nas artes comerciais publicitárias atuando como atrativo pelo viés do desejo, transformando o corpo num híbrido no qual corpo e produto se misturam. Desta forma, o texto disserta sobre a relação paradoxal do corpo na teologia clássica cristã, no protestantismo e na contemporaneidade através do cenário gospel, demonstrando o processo de traslado e apropriação dentro da cultura visual evangélica, da lógica de mercado secular e consequentemente do uso da sedução como instrumental do marketing religioso.

Palavras-chave: Mercado Gospel; Sensualidade; Corpo; Cultura Visual.

\section{THE RECOURSE TO SENSUALITY AS A STRATEGY OF THE GOSPEL MARKET}

\section{ABSTRACT}

This article aims to analyze the use of eroticism and seduction as part of the marketing strategy present in the productions of gospel "artists" from the 1990s. In western consumer society, the use of

* Doutora em Ciências da Religião. Professora do Programa de Pós-Graduação em Ciências da Religião da Universidade Metodista de São Paulo e coordenadora do Grupo de Estudos de Gênero e Religião Mandrágora/NETMAL.sanduarte3@gmail.com

**Doutor em Ciências da Religião na área de concentração: Religião, Sociedade e Cultura pela Universidade Metodista de São Paulo (2019). Participante dos grupos de pesquisa: Grupo de Estudos de Gênero e Religião Mandrágora/NETMAL e do Rimago - Cultura Visual Religiosa. jmdidio@gmail.com 
image carries a considerable burden of exploration of its corporeality. In this sense, sensuality and visual eroticization become components present in the commercial advertising arts acting as an attraction for the bias of desire, transforming the body into a hybrid in which body and product mix. Thus, the text discusses the paradoxical relationship of the body in classical Christian theology, Protestantism and contemporaneity through the gospel scenario, demonstrating the process of transfer and appropriation within the evangelical visual culture, secular market logic and consequently the use of seduction as an instrument of religious marketing.

Key Words: Gospel Market; Sensuality; Body; Visual Culture.

\section{EL RECURSO A LA SENSUALIDAD COMO ESTRATEGIA DEL MERCA- DO GOSPEL}

\section{RESUMEN}

Este artículo tiene como objetivo analizar el uso del erotismo y la seducción como parte de la estrategia de marketing presente en las producciones de "artistas" gospel desde la década de 1990. En la sociedad de consumo occidental, el uso de la imagen en estas producciones se carga de importante exploración del cuerpo. En este sentido, la sensualidad y la erotización visual se convierten en componentes presentes en las artes publicitarias comerciales que actúan como una atracción por el sesgo del deseo que transforma el cuerpo en un híbrido en el que se mezclan cuerpo y producto. Por lo tanto, el texto discute la relación paradójica del cuerpo en la teología cristiana clásica, el protestantismo y la contemporaneidad a través del escenario del evangelio, demostrando el proceso de transferencia y apropiación dentro de la cultura visual evangélica, la lógica del mercado secular y, en consecuencia, el uso de la seducción como instrumento de marketing religioso.

Palabras-clave: Mercado Gospel; Sensualidad; Cuerpo; Cultura Visual.

\section{INTRODUÇÃO}

O título do presente artigo pode parecer contraditório. Como recorrer à sensualidade dentro de uma tradição que historicamente visa o controle dos corpos, de seus desejos e manifestações? Em que medida o recurso à sensualidade rompe com uma tradição que durante séculos condenou o corpo a uma rigorosa disciplina? Há efetivamente uma ruptura? 
O Cristianismo, desde o seu início, não se furtou à discussão sobre o corpo. Antônio Maspoli de Araújo Gomes, ao tratar das representações sociais do corpo no protestantismo, afirma que a teologia paulina sobre o corpo, ao mesmo tempo que o reconhece como "templo do Espírito Santo", também o abomina como expressão do pecado humano:

Paulo apresenta o corpo como um objeto paradoxal. Se, por um lado, é alçado à condição de templo do Espírito Santo, por outro é marcado pela carne, a natureza adâmica decaída. Este dualismo paulino moldou o pensamento da patrística e se faz presente até hoje nas imagens que o Protestantismo cunhou sobre este tema (Antônio GOMES, 2006, p. 5).

Segundo Antonio Gomes, para o apóstolo Paulo, o corpo é expressão da natureza humana pecaminosa e é incapaz de transcender suas origens terrestres, batalhando permanentemente com o Espírito (2006, p. 6). Essa percepção vai se estender e se fortalecer ao longo dos anos, em especial com os Pais da Igreja, e vai sofrer significativa mudança a partir de Santo Agostinho no século IV, que apresenta uma compreensão menos negativa do corpo. De qualquer forma, a regulação do corpo e da sexualidade é uma das ênfases de seus escritos.

O corpo foi dissecado e dissertado pela teologia clássica, que ao tratar do mesmo, direcionou seu olhar especialmente para a sexualidade. Esta foi objeto de extensos tratados teológicos ${ }^{1}$, e esteve presente nas mais diversas formas de expressão dos pensadores da Igreja, em especial quando os mesmos se referiam às mulheres, alvo preferencial da abjeção teológica que se pautava na afirmação de que as mulheres, por sua natureza, seriam mais vulneráveis e mais pecaminosas do que os homens:

Embora homens e mulheres estivessem sujeitos aos tormentos do desejo sexual, achava-se que as mulheres provavelmente estivessem mais sob o seu domínio do que os homens. [...] Devido ao seu papel bíblico como tentadoras, as mulheres eram consideradas naturalmente mais expostas que os homens ao perigo sexual (Robin SCHOTT, 1996, p. 64).

A esse respeito, ver "A virgindade consagrada”, de Agostinho (1990), e "Ética - Fundamentos, Oração, Sexualidade”, de Lutero (1995). 
Isso pode se verificar na insistente tentativa de Agostinho (2004), Tomás de Aquino (1980), Lutero (1955) e Calvino (1998) de apresentarem as mulheres como humanas menores do que os homens, mais suscetíveis às tentações e, portanto, mais necessitadas de controle. Para esses teólogos, tal controle deveria ser realizado por homens, que teriam maior domínio sobre sua natureza (Robin SCHOTT, 1996).

O protestantismo emerge em meio a um contexto social de regulação em que se produziam manuais para se garantir "a submissão e a obediência do corpo, e (...) o cultivo das boas-maneiras, da decência e do decoro" (Roy PORTER, 1992, p. 310). Isso impacta a percepção protestante sobre o corpo.

Ao longo de sua história, o protestantismo tem identificado o corpo com o pecado, e tal identificação, tende à sua negação e disciplinamento. O corpo é visto de forma fragmentada, separado do espírito. Os desejos mais íntimos são perseguidos para serem publicizados socialmente, e assim, provocarem o castigo daqueles e daquelas que se deixam envolver pela sedução da vida corpórea.

A regulação da vida sexual, a tutela do desejo, a definição daquilo que se pode e não se pode falar, vestir, mostrar ou insinuar, compõem um amplo acervo de restrições impostas à sociedade pelo poder eclesiástico e por seus mecanismos de controle. Tal controle só pode ser entendido se compreendermos que o próprio corpo está inserido num campo político.

\section{A PRODUÇÃO SOCIAL DOS CORPOS: A SENSUALIDADE POSITIVADA PELO MERCADO}

Um corpo não é apenas um corpo. É também seu entorno. Mais do que um conjunto de músculos, ossos, vísceras, reflexos e sensações, o corpo é também a roupa e os acessórios que o adornam, as intervenções que nele se operam, a imagem que dele se produz, as máquinas que nele se acoplam, os sentidos que nele se incorporam, os silêncios que por ele falam, os vestígios que nele se exibem, a educação de seus gestos (Silvana GOELLNER, 2003, p. 29).

A materialidade do corpo não se restringe à sua anatomia. O corpo é um emaranhado de significados socioculturais, o que significa dizer 
que ele está situado culturalmente e é produzido socialmente. Por ser agente cultural, os sentidos atribuídos ao corpo variam conforme o contexto histórico-cultural em que se está inserido, isto é, nossos corpos são cunhados, inscritos pela cultura.

A produção social dos corpos implica percebê-los como produtos de relações de poder, poder este que age sobre a vida concreta dos sujeitos, e que não está dedicado principalmente a reprimir forças, mas sim a alimentá-las, fazendo-as crescer, investindo o corpo do sujeito (Michel FOUCAULT, 2013).

Para Foucault, as relações de poder e dominação que envolvem os corpos visando torná-los dóceis e produtivos, precisam da sua sujeição. Em outras palavras, os esforços de regulação dos corpos seriam essencialmente esforços de manutenção da sua sujeição. Foucault sustenta ainda que o corpo é um lugar prático de controle, e haveria um investimento político nele visando sua utilização econômica: "o corpo só se torna força útil se é ao mesmo tempo corpo produtivo e corpo submisso" (2013, p. 29), isto é, corpo útil e corpo dócil. A produção social dos corpos, de uma ou outra maneira, se orienta por esse objetivo.

Ao tratarmos das relações do mercado com o corpo, nos deparamos com um padrão que orienta a cultura do consumo. A ideia de um corpo de referência, de um "corpo que vende", tem gerado as mais diversas intervenções nos corpos, orientados por esse padrão, desde inúmeras dietas a operações plásticas e bariátricas. O recurso ao photoshop ${ }^{2}$ que "conserta o corpo" para corresponder à expectativa do mercado, também revela a predominância desse padrão.

O corpo de referência gera ainda mais interesse de quem o consome se for revestido de sensualidade. Isso pode se verificar, por exemplo, nas pesquisas que têm se dedicado a investigar a forma como se representam as mulheres nos jogos eletrônicos. Yi Mou e Peng Wei (2009), após analisarem 19 jogos, concluíram que a hipersensualização é a forma predominante de representação da mulher nesses games,

Software produzido pela Adobe System fundada em 1982, o Photoshop é um programa de geração de imagens e design gráfico que permite criar e editar imagens, incluindo retoques estéticos, mudanças de cores e luminosidade. Ele se tornou uma das ferramentas mais conhecidas e utilizadas na área. Ver: http://www.photoshop.com/. 
que é sempre magra e está sempre trajada de forma a deixar exposta a maior parte do seu corpo.

A publicidade de forma geral tem investido há décadas na estratégia da sensualização para a venda de produtos diversos. Haveria uma conjunção entre mercado, sensualidade e erotismo. Como bem destaca Edgar Morin,

O dinheiro sempre insaciável se dirige ao Eros, sempre subnutrido, para estimular o desejo, o prazer, e o gozo, chamados e entregues pelos produtos lançados no mercado. O erotismo entra triunfalmente no circuito econômico dotado de poderes e envolve fortemente a civilização ocidental (Edgar MORIN, 1997, p.120).

A apropriação e o estímulo à sensualidade dos corpos pelo mercado, também se verifica no âmbito religioso. O chamado "mercado gospel” tem investido importantes esforços na produção de imagens mais "palatáveis" de seus artistas para o público consumidor, afastando-se da estética protestante de décadas anteriores, como veremos a seguir.

\section{EROTISMO E SEDUÇÃO DOS/AS “ARTISTAS" GOSPEL}

Nas últimas décadas, o mercado gospel tem alcançado sucesso de venda de produtos dos mais diversos. CDs, DVDs, roupas, objetos, shows, palestras, dentre outros produtos, compõem um conjunto de mercadorias e serviços do mundo gospel que atraem consumidores e consumidoras, evangélicos/as ou não. Tais produtos, ao longo dos anos, passaram por um processo de "aprimoramento estético", e um dos resultados dessa transformação, foi a sensualização da imagem de artistas desse segmento, em especial de cantoras e cantores evangélicos.

O marketing das produtoras fonográficas do universo gospel tem priorizado a imagem de seus artistas. Um mero exercício comparativo de capas de CDs e DVDs lançados recentemente, com capas de discos de vinil das décadas de 1980 e 1990 explicita o crescente investimento desse setor no melhoramento e na sensualização dessa imagem como estratégia para estimular o consumo de seus produtos.

O pano de fundo desse processo parte do problema de que as instituições religiosas evangélicas, diante da produção visual do gospel 
(como outras produções artísticas pertencentes a este segmento), não detém mais o controle da sistematização e da legitimação artística de suas produções. Tal controle e regulação manteve força até meados da década de 80. A partir dos anos 90, com o crescimento do mercado gospel, mecanismos mercadológicos são instituídos por meio do marketing estabelecido pelas produtoras fonográficas, o que fomentou o consumo e a legitimação dos artistas.

Para Lísias Negrão, este "mercado na religião e religião de mercado" enfatiza a preocupação com as novas formatações do campo religioso diante de um contexto onde o mercado triunfa: "frente à crise das religiões tradicionais, à fragmentação e à instrumentalização das novas religiões pelo próprio mercado, as suas características transcendentes e totalizadoras o “deificaram'” (Lísias NEGRÃO, 2000, p. 61). Esse processo do mercado implica em elementos deificadores para o contexto do gospel, imprimindo nesta cultura, mecanismos de construção de um mercado evangélico independente das instituições religiosas onde a imagem faz parte como produto visual.

Com esta independência do controle eclesiástico, no que tange à produção imagética, o mercado gospel gerou um descolamento de elementos repressores do corpo. A mola propulsora para este movimento foi a cooptação pelo mercado evangélico da lógica iconográfica secular do marketing, promovendo a implementação e o desenvolvimento de um novo paradigma do corpo evangélico. Nisso, o processo de legitimação foi realocado para as imagens, sendo elas o veículo utilizado para a validação do erótico e do sensual na corporeidade gospel.

O paradigma do erotismo e da sedução apresentado nas produções no gospel estão diretamente associados ao referencial do consumo trasladado mimeticamente do mercado secular, sendo utilizado como mecanismo de atração junto ao consumidor evangélico.

O uso do corpo-imagem da mulher como instrumento de sedução através do erótico não é novo para o mercado. Vemos isso em propagandas de bebidas, carros, roupas e produtos seculares direcionados ao público masculino. 
Figura 1 - CD Fernanda Brum

- Cura-me (2008)

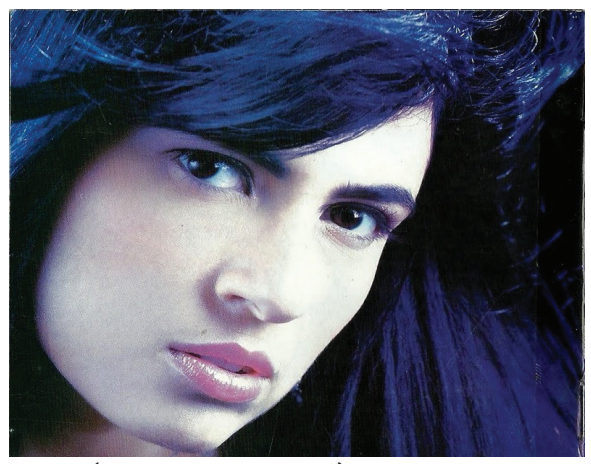

Fonte: (Encartes Pop, 2008)
Figura 2 - Close

Fotográfico Sensual

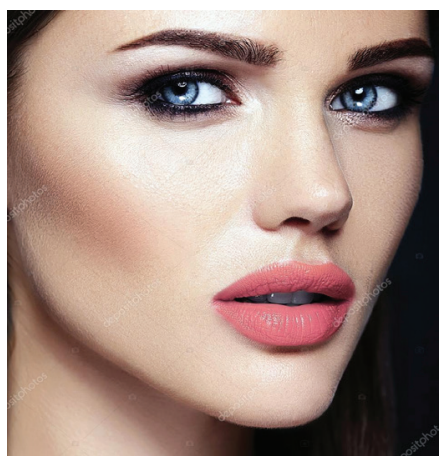

Fonte: (HALAY, 2016)

No caso do CD da cantora gospel Fernanda Brum³ (fig.1), observa-se a utilização do corpo-erótico como instrumento de sedução. A partir de uma análise iconológica (Erwin PANOFSKY, 1955), a figura 1 apresenta uma mulher branca com cabelos pretos. A construção da foto tem como base o close fotográfico com o olhar da mulher de perfil direcionado ao observador, os lábios entreabertos com batom de cor rosada. A imagem passou por tratamento digital para remoção de imperfeições estéticas e clareamento no rosto, nariz e testa.

A composição da fotografia e os tratamentos de pós-produção foram trasladados dos paradigmas seculares presentes na figura 2. Do ponto de vista do corpo-imagem, corpo-erótico e corpo-capital (Jean BAUDRILLARD, 2008), a representação iconográfica apresentada na figura 1, mostra um corpo que é consumido e incorporado pelo mercado gospel, compreendendo que a questão do consumo de corpos femininos é parte de uma construção cultural que privilegia a exploração do corpo da mulher como objeto de desejo e consumo. É a partir deste corpo-objeto constituído para o consumo que observamos o sentido enfeitiçador destacado por Baudrillard:

O que pretendemos mostrar é que as estruturas actuais da produção/consumo induzem no sujeito uma dupla prática, conexa com

Cantora gospel e pastora evangélica, iniciou sua carreira lançando seu primeiro LP em 1993, intitulado Feliz de Vez. 
a representação desunida (mas profundamente solidária) do seu próprio corpo: o corpo como CAPITAL e como FEITIÇO (ou objecto de consumo). Em ambos os casos, é necessário que o corpo, longe de ser negado ou omitido, se invista (tanto no sentido econômico como na acepção psíquica do termo) com toda determinação (Jean BAUDRILLARD, 2008, p. 169).

Na sociedade consumista, o corpo feminino e masculino (num nível menor) é requerido como atrativo/produto de desejo, sofrendo pressões do mercado no sentindo de manter uma boa aparência estética, como parte fundamental para aceitação. Entretanto, parecer bem para a sociedade contemporânea, significa estar sexualmente atrativo/a, o que corresponde diretamente a corpos esculpidos, jovens, atraentes (eros), retocados, em movimentos, ornando com ambientes produzidos, cores, mas que seja um corpo magro (Maria CUNHA, 2014).

Este ambiente está despontando como um grande divulgador e acelerador da empreitada destas personalidades, além de constituir outra ressignificação para o corpo. Do corpo biofísico para o corpo-imagem como discute Klein, "são aspectos desse fenômeno que restringe a experiência dos vínculos físicos e afetivos gerados pelo corpo e estimula a instrumentalização de um corpo-imagem, eternamente jovem e saudável" (Alberto KLEIN, 2006, p. 91).

Isto somente reforça que "cada vez mais a performance, o look, a estetização da vida ganham espaço no rol de preocupações das pessoas" (Ana CASTRO, 2001) e que o erótico e o sensual não estão fora da indústria cultural evangélica e dos mecanismos midiáticos das redes sociais que exercem poder e controle sobre o que é esteticamente aceitável. Assim, essa ótica da sensualidade e do erotismo (fig. 1 e 2) tem sido utilizada pela iconografia gospel em suas produções de CD e DVD desde o início da década de 90 (João SILVA, 2010).

De forma análoga ao processo utilizado nas produções de imagens femininas para o marketing gospel, as produções masculinas também utilizam elementos do erótico e da sensualidade para tornar suas produções mais atraentes, visando alcançar o consumo do público feminino. O binômio erótico-sedução se apresenta de forma similar aos conceitos utilizados nas mulheres. 
Figura 3 - Cantor

Stéfanno Dias (2015)

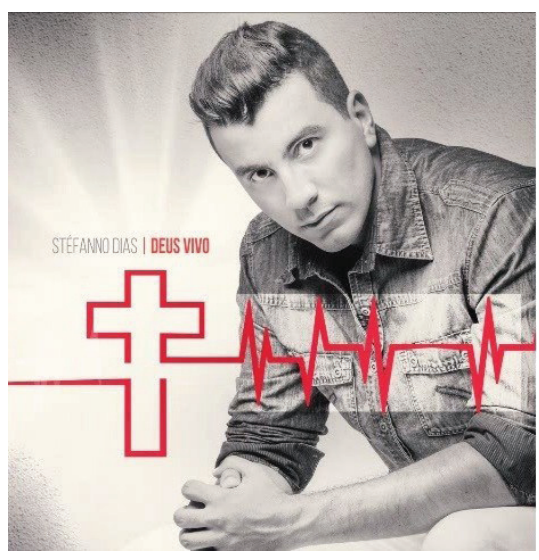

Fonte: (Stéfanno Dias, 2015)
Figura 4 - Cowboy Marlboro (década de 1970)

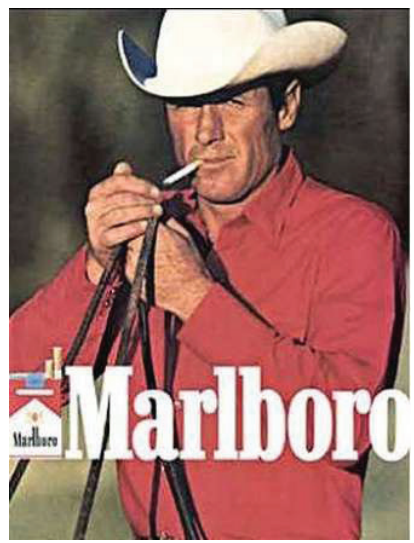

Fonte: (Eric Lawson, 2014)

No aspecto iconológico, a foto do cantor gospel Stéfanno Dias (fig.3), se caracteriza pelo close fotográfico (fig.3A). O cantor conduz o olhar fixo no consumidor (neste caso, em grande parte feminino); com a boca fechada (a boca sensual semiaberta é utilizada nas fotos de mulheres), cabelo curto e barba feita seguindo mimeticamente o paradigma do Marlboro Man que foi construído no imaginário brasileiro nos anos 80 . O cowboy (fig.4) representando o estilo do homem 'durão', permeou tanto imagens de marketing, como personagens de artistas televisivos cumprindo uma função simbólica que constitui o "imaginário da publicidade, da fotografia de moda [...] das estrelas do cinema e dos media" (José RIBEIRO, 2004, p. 41).

O poder do erótico e da sedução neste momento, se torna fundamental para o alcance do objetivo. Em Foucault, o poder da sexualidade influencia o corpo pelo viés do prazer. Assim, a utilização deste corpo-imagem-erótico na produção visual tem o poder de controlar e ressignificar o corpo como objeto de consumo.

O poder que, assim, toma a seu cargo a sexualidade, assume como um dever roçar os corpos; acaricia-os com os olhos; intensifica regiões; eletriza superfícies; dramatiza momentos conturbados. 
Açambarca o corpo sexual. Há sem dúvida aumento da eficácia e extensão do domínio sob controle, mas também sensualização do poder e benefício de prazer. (Michel FOUCAULT, 1985, p. 44)

Figura 5 - Cantora gospel

Figura 6 - Cantora Madonna

Shana Saint

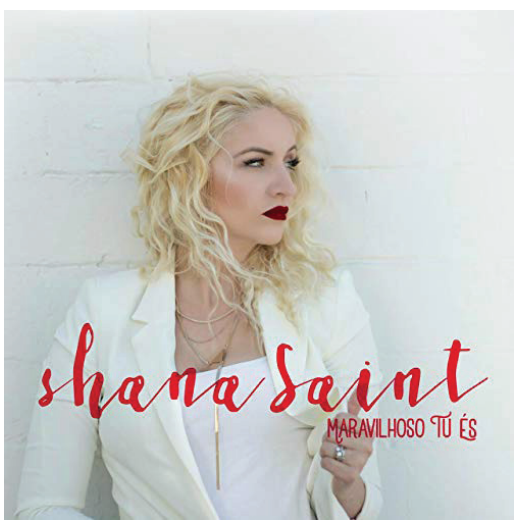

Fonte: (Shana Saint, 2016)

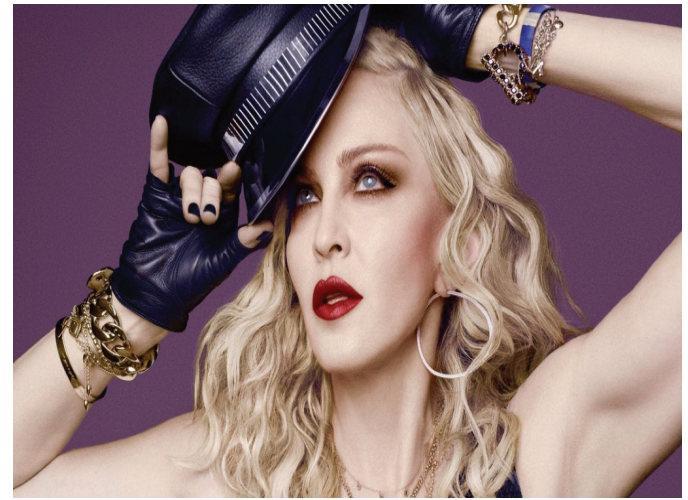

Fonte: (Madonna, 2018)

No caso feminino, os traslados do mercado secular acontecem juntamente com a existência de normas reguladoras que materializam o sexo (Maria CUNHA, 2014). Com isso se nota, nas figuras 5 e 6, que a erotização permeia a iconografia feminina gospel ao procurar utilizar- se de paradigmas já estruturados e "de sucesso".

A escolha por referências de imagens seculares perpassa pelo conceito de fórmula de páthos desenvolvido por Aby Warburg (18661926), afirmando que as imagens possuem uma energia emocional, uma força psicológica, que consiste na força oriunda das pulsões internas, presente através de gestos e expressões corporais que remetem, como uma lembrança, a experiências e comoções originais, numa espécie de memória social da imagem (Aby WARBURG, 2010), como é possível observar nos destaques na figura 6 da artista Madonna.

A figura 5 da cantora gospel Shana Saint ${ }^{4}$ demonstra os traslados estadunidenses para o mercado evangélico brasileiro e a utilização do

Shana Saint é uma cantora estadunidense que tem gravado músicas em português para alcançar o mercado brasileiro. Em maio de 2019 fez uma participação no CD Terceiro Céu da cantora brasileira Fernanda Brum. ver: https://www.shanasaint.com/ 
páthos presente na figura 6 da cantora Madonna que representa, desde a década de 80, a imagem de uma girl power, símbolo da sensualidade, do erotismo e da liberação do corpo feminino.

Isto aponta que o mercado evangélico, do ponto de vista iconográfico, se apropria dos paradigmas seculares de produção visual, buscando absorver a força do erótico e da sedução presente nestes modelos, para que, incorporados em suas produções, possam seduzir o consumidor, não pelo aspecto do discurso de sua mensagem evangélica, mas pela força da imagem. Baitello explicita neste sentido a questão: "Toda imagem se apropria de imagens precedentes e bebe nelas ao menos parte de sua força" (Norval BAITELLO, 2005, p. 95).

Apesar da utilização da força do eros e do sensual no contexto gospel, a questão está permeada de contradições. No caso dos/as artistas, quando se trata da liberdade do corpo feminino gospel fora da publicidade, as regulações não são relativizadas e o controle é mais rígido.

Artistas (mulheres) gospel se pronunciam criticando e questionando o controle que a religião exerce sobre seus corpos quanto ao uso de roupas de banho (biquínis são rechaçados, maiôs tolerados e algumas artistas preferem cobrir totalmente o corpo) em fotos publicadas em redes sociais em que exponham o corpo.

Figura 7- Instagram Cantora Pamela

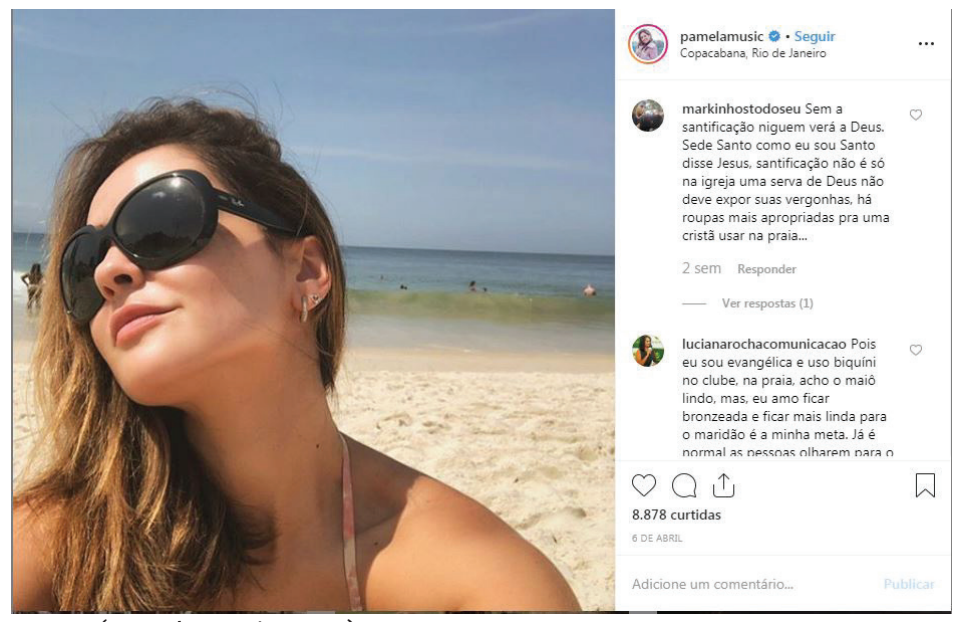

Fonte: (Pamela Music, 2019) 
Um desses pronunciamentos vem da cantora gospel Pamela que publicou um texto em sua conta da rede social Instagram criticando o controle de seu corpo.

Antes de postar essa foto eu fiquei tentando cortar a foto pq "pegaria mal" eu postar uma foto no meu Instagram aparecendo uma parte do meu biquíni. [...] Pois é, eu to cansada de viver dentro dessa bolha pq fulano ou ciclano da internet (que eu nem conheço) vai ficar falando da minha foto, sendo que eu mesma não devo nada pra ninguém e ninguém tem nada haver [sic]com a minha vida!" (Pamela Music, 2019)

Percebe-se por meio desse discurso que a questão da regulação dos corpos permanece, de forma contraditória com as produções visuais do marketing. O interdito da exposição do corpo na vida privada e o uso do erótico e da sensualidade na cultura visual gospel permanece como forma de exploração do corpo-produto dentro deste cenário, corroborando para a regulação teológico-social-cultural dos corpos femininos.

\section{CONSIDERAÇÕES FINAIS}

A relação entre o corpo, gênero e consumo na realidade midiática contemporânea, transforma os corpos em veículos de manipulação junto à sociedade imagética. "No ambiente atual, os corpos manipulam seus espectadores: eles se mostram como corpos de beleza sobre-humana, ou como corpos virtuais, que abandonaram os limites do corpo natural" (Hans BELTING, 2007, p. 111). Ambos os corpos - feminino e masculino - são transformados em objetos de voyerismo visual e da busca do prazer na cultura de consumo.

Com o uso do erótico e do sensual na vida pública comercial dos artistas e da regulação dos corpos e controle moral na vida privada, o contraditório permanece nas representações imagéticas no gospel, que por um lado é liberado para consumo, exploração material, iconográfica e cultural e por outro, rechaçado como instrumento de vergonha e pudor por parte do público evangélico.

Com o controle por parte das produtoras fonográficas nas produções imagéticas gospel, a mercantilização e as exigências de mercado do corpo feminino são retroalimentadas constantemente. Neste cenário 
as artistas e os artistas gospel passaram a ressignificar a aparência estética, modificando sua relação com o corpo através de procedimentos de emagrecimento, cirurgias plásticas estéticas corretivas e transformadoras, maquiagem, vestuário, no intuito de se distanciar do visual e do corpo 'crente' das décadas anteriores, direcionando-o para uma corporeidade e moda secular que fortaleça o eros, atrelado ao "espírito" do evangélico moderno.

\section{REFERÊNCIAS}

AGOSTINHO, Santo. A virgindade consagrada. São Paulo: Paulinas, 1990.

BAITELLO, Norval. A Era da Iconofagia: Ensaios de comunicação e cultura. São Paulo: Hacker Editores, 2005.

BAUDRILLARD, Jean. A sociedade de consumo. Lisboa: Edições 70, 2008.

BELTING, Hans. Antropología de la imagen. Argentina: Katz Editores, 2007.

CALVINO, João. As Pastorais. São Paulo: Paracletos, 1998.

CASTRO, Ana Lucia de. Culto ao corpo e sociedade: Mídia, cultura de consumo e estilos de vida. Tese Campinas: Tese (Doutorado em Sociologia). 183f. Instituto de Filosofia e Ciências Humanas, Universidade de Campinas, Campinas, 2001. Disponível em <http:// repositorio.unicamp.br/jspui/handle/REPOSIP/280088>. Acesso em: 12 ago. 2019.

CUNHA, Maria João. Corpo e Imagem na sociedade do consumo. Lisboa: Clássica Editora, 2014.

FOUCAULT, Michel. Vigiar e punir. Petrópolis: Vozes, 2013.

GOELLNER, Silvana. A produção cultural do corpo. In: LOURO, Guacira, NECKEL, Jane e GOELLNER, Silvana (Orgs.) Corpo, gênero e sexualidade: um debate contemporâneo na educação. Petrópolis: Vozes, 2003, p. 28-40.

GOMES, Antônio Máspoli de Araújo. As Representações Sociais do Corpo e da Sexualidade no Protestantismo Brasileiro. Rever, n. 1, 2006, p. 1-38. Disponível em: <https:// www.pucsp.br/rever/rv1_2006/p_gomes.pdf>. Acesso em: 12 ago. 2019.

KLEIN, Alberto. Imagens de culto e imagens da mídia: Interferências midiáticas no cenário religioso. Porto Alegre: Sulina, 2006.

LUTERO, Martinho. Ética - Fundamentos, Oração, Sexualidade. Vol. 5 Sinodal, 1995.

LUTHER, Martin. Luther's Works. In: PELIKAN, Jaroslav; ZEHMANN, Helmut. Luther's Work. St. Louis: Concordia Publishing House, 1955

MORIN, Edgar. Cultura de massa no século XX. Rio de Janeiro: Forense/Neurose, 1997. MOU, Yi; WEI, Peng. Gender and Racial Stereotypes in Popular Video Games. Handbook of Research on Effective Electronic Gaming in Education. IGI Global, 2009, p. 922-937. 
NEGRÃO, Lísias Nogueira. "Mercadolicismo" - mercado na religião e religião do mercado. Estudos de Religião, n. 18. São Bernardo do Campo: Universidade Metodista de São Paulo, 2000, p. 61.

PAMELA MUSIC. Disponível em: <https://www.instagram.com/p/Bv6-IpTJayd/?utm source=ig_web_copy_link>. Acesso em: 23 de mai. de 2019.

PANOFSKY, Erwin. Significado nas artes visuais. São Paulo: Perspectiva, 1955.

PORTER, Roy. História do corpo. In: BURKE, Peter (Org.). A Escrita da História: Novas perspectivas. São Paulo: UNESP, 1992.

RIBEIRO, José Silva. Antropologia visual - Da minúcia do olhar ao olhar distanciado. Lisboa: Edições Afrontamento, 2004.

SILVA, João Marcos da. As Feias (e os feios) que me desculpem, mas beleza é fundamental": O uso contemporâneo da imagem e sua influência na mudança dos paradigmas estéticos utilizados na música gospel no Brasil. 115f. Dissertação (Mestrado em Ciências da Religião). Programa de Pós-Graduação em Ciências da Religião, São Bernardo do Campo: Universidade Metodista de São Paulo, 2010.

SCHOTT, Robin. Eros e os processos cognitivos: Uma crítica da objetividade em filosofia. Rio de Janeiro: Rosa dos Tempos, 1996.

WARBURG, Aby. Histórias de fantasma para gente grande: Escritos, esboços e conferências. São Paulo: Companhia das Letras, 2010.

WARBURG, Aby et al. Historia de las imágenes e historia de las ideas: La escuela de Aby Warburg. [S.I.]: Centro Editor de América Latina, 1992.

Submetido em: 31-10-2019

Aceito em: 20-11-2019

Mandrágora, v.25, n. 2, 2019, p. xx-xx 